\title{
Nuclear Safety of Extended Sludge Processing on Tank 42 and 51 Sludge (DWPF Sludge Feed Batch One)
}

by

J. S. Clemons

Westinghouse Savannah River Company

Savannah River Site

Aiken, South Carolina 29808

This paper was prepared in connection with work done under the above contract number with the U.S. Department of Energy. By acceptance of this paper, the publisher and/or recipient acknowledges the U. S. Government's right to retain a nonexclusive, royalty-free license in and to any copyright covering this paper, along with the right to reproduce and to authorize others to reproduce all or part of the copyrighted paper. 


\section{DISCLAIMER}

This report was prepared as an account of work sponsored by an agency of the United States Government. Neither the United States Government nor any agency thereof, nor any of their employees, makes any warranty, express or implied, or assumes any legal liability or responsibility for the accuracy, completeness, or usefulness of any information, apparatus, product, or process disclosed, or represents that its use would not infringe privately owned rights. Reference herein to any specific commercial product, process, or service by trade name, trademark, manufacturer, or otherwise does not necessarily constitute or imply its endorsement, recommendation, or favoring by the United States Government or any agency thereof. The views and opinions of authors expressed herein do not necessarily state or reflect those of the United States Government or any agency thereof.

This report has been reproduced directly from the best available copy.

Available to DOE and DOE contractors from the Office of Scientific and Technical Information, P.O. Box 62, Oak Ridge, TN 37831; prices available from (615) 576-8401.

Available to the public from the National Technical Information Service, U.S. Department of Commerce, 5285 Port Royal Road, Springfield, VA 22161. 


\section{DISCLAIMER}

Portions of this document may be illegible electronic image products. Images are produced from the best available original document. 
HIGH LEVEL WASTE E.YGINEERING

HIGH LEVEL EYGINEERING SL'PPORT

\section{UNCLASSIFIED}

NUCLEAR SAFETY OF.

EXTENDED SLUDGE PROCESŚING

ON TANK 42 AND 51 SLUDGE

(DWPF SLLDGE FEED BATCH O:IE). (U)

BY

J. S. CLEMMONS

ISSUED: February 26, 1993
WSRC-TR-93-t15

REVISION: 0

KEYWORDS:

Criticality Safery

Sludge

ESP

Lranium-235

Plutonium-239

RETENTION: PERMANENT

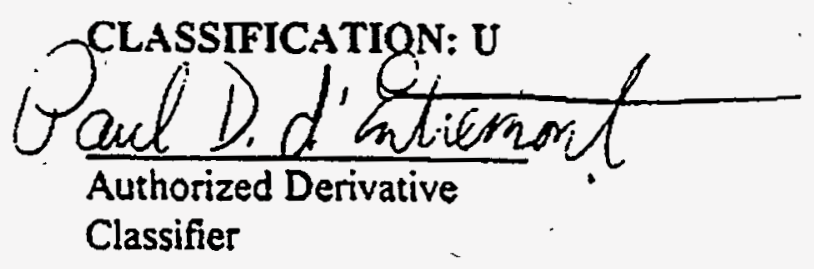

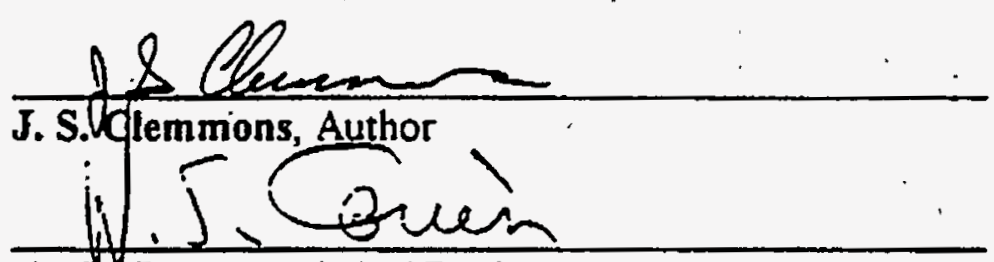

W. S. Cavin, Technical Reviewer

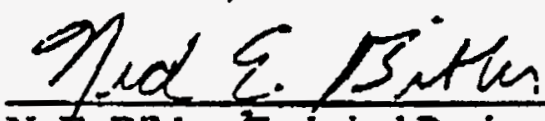

N. E. Bibler, Technical Reviewer

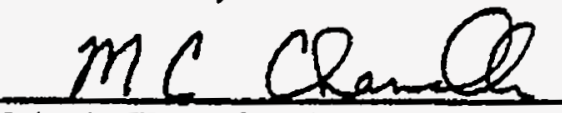

M. C. Chandler, Manager, HILLW Technologies Studies

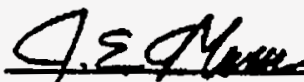

J. E. Marra, Manager, HIW Engineerıq Support

d.e. Dickect tr Unintonator

T. M. Monahon, Mąnager, HLWE (Approved)
Date: $2 / 26 / 53$

Date: $3 f 26 / 93$

Date: $2 / 26 / 73$

Date: $3 / 1 / 93$

Date: $3 / 1 / 93$

Date: $3 / 1 / 93$

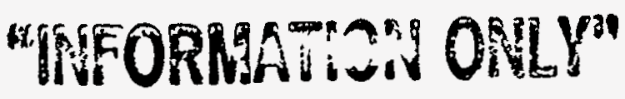




\section{TNTRODLCTIOY.}

The sludge in tanks $t 2$ and 51 is to be washed with inhibited water to remove soluble saits and combined in tank $3 l$ in preparation for feed to DWPF. Since these tanks contain uranium and plutonium, the process of washing must be evaluated to ensure subcriticality is maintained. When the siudge is washed. inhibited water is added, the tank contents are slurried and allowed to settle The sludge wash water is then decanted to the evaporator feed tank where it is fed to the evaporator to reduce the volume. The resulting evaporator concentrate is sent to a salt tank where it cools and forms crystallized salt cake. This salt cake will later be dissolved, processed in ITP and sent to Z-Area. This report evaluates the supernate and sludge during washing, the impact on the evaporator during concentration of decanted wash water, and the salt tank where the concentrated supernate is deposited. The conclusions generated in this report are specific to the sludge currently contained in tanks 42 and 51 .

\section{SUMMARY}

The contents of tank 42 and 51 may be washed with inhibited water and combined in tank 51 without the risk of criticality. The dilute concentration of fissile material in the sludge combined with an excess of neutron absorbers before, during and after washing make criticality in tanks 42 and 51 incredible. Prior sludge washing experience indicates that there is insufficient fissile material dissolved in the wash water to impact the safe operation of the evaporator system. The fissile material concentration in the washes will be monitored for continued confirmation through sampling during the Extended Sludge Processing (ESP) operation.

\section{DISCUSSION}

\section{Waste Tank Sludge}

There are three characteristics of SRS waste tank sludge that make criticality incredible [5], insufficient areal density of fissile material, insufficient concentration of fissile material and an excess of neutron absorbers present in the sludge. To evaluate the nuclear safety of sludge washing, the effect of washing on areal density, concentration and neutron absorbers must be determined. Comparison of fissile material areal density and concentration to safe values requires an estimate of the fissile material in a tank. Three estimates of the fissile material content tor both tanks 42 and 51 have been performed. The results of these estimates are listed in tables $l$ and 2 respectively. 
IISRC-TR-93.115,

Rev 0

Page 3

Table 1. Tank +2 Estimated Fissile XIaterial Content.

Parameter

Total L'ranium (kgs)

U.235 (kgs)

U-235iTotal L' (wt.\%)

Plutonium-239 (kgs)

Sludge V'olume (kgals)

Tank Surface Area ( $\mathrm{f}^{2}$ )

U-235 Areal Density $\left(g / \mathrm{f}^{2}\right)$

Pu-239 Areal Density (g/ $\mathrm{A}^{2}$ )

U-235 Concentration ( $g / l)$.

Pu-239 Concentration ( $g / /)$

\section{ALPHA}

$5063^{3 *}$

$388^{*}$

$077 \%$

$2+2$

260

$56+6$

69

4.3

0.039

0025
Sample Data[10]

8502

$\$ 7.9$

$0563 \%$

33.7

260

5646

8.6

4.4

0.049

0.025
ALPHA II [1]

3364

23.5

$07 \%$

27.8

260

5646

4.2

4.4

0.024

0.025

* ALPHA does not account for uranium transferred out during tank 42 ESP demo

Table 2. Tank 51 Estimated Fissile Material Content.

\section{Parameter}

Total Uranium (kgs)

$\mathrm{U}-235$ (kgs)

U-235/Total U (w.\%)

Pu-239 (kgs)

Sludge Volume (kgal)

Tank Surface Area $\left(\mathrm{ft}^{2}\right)$

U-235 Areal Density $\left(g / \mathrm{t}^{2}\right)$

Pu-239 Areal Density $\left(g / \mathrm{At}^{2}\right)$

U-235 Concentration ( $\mathrm{g} / \mathrm{l})$

$\mathrm{Pu}-239$ Concentration (g/l)

\section{ILPHA \\ 7687}

26.3

$0.34 \%$

23.6

263

5646

$+7$

$+2$

0026

0024

$\frac{\text { Sample Data }}{9200}[2,9]$

$0.52 \%$

54

263

5646

8.6

.9 .5

0.048

0.054

\section{ALPHA M[4] , 4978}

15.4

$0.31 \%$

13.6

263

5646

2.7

2.4

0.016

0.014

The ALPHA estimates are based on accountability data and are known to have questionable accuracy. The sample estimates are determined by taking the concentrations found in the sample volume and multiplying by the volume of sludge in the waste tank. The ALPHA II estimates are based on a recreation of canyon waste discharges coupled with a recreation of the waste tank receipt and transfer history. The Pu-239 and U-235 mass estimates are not equal, however all of the estimates show that tanks 42 and 51 contain $U$ with an $U-235$ content at or below that of natural $U$ and that the concentration and areal density of U-235 and Pu-239 are extremely low. For comparison to safe values, the estimates determined from sample analysis will be used. This is conservative since the sample data indicates the largest amount of $\angle$ and $\mathrm{Pu}$. Based on the amount of previous slurtying associated with transfer and washing. the contents of tank 42 and 51 should be well mixed. Additional washing and slurn ing of the tank contents will provide further mixing. t. 
IVSRC-TR-93-115

Rev. 0

Page 4

Based on the sample estimates from table 1 and 2 . when the sludge in tank 72 is combined with that in tank 51 , the equivalent Pu-239 (conservatively assuming all $C_{-235}$ is $\mathrm{P}$ Li-239) areal density and concentration will be $31 \mathrm{lg} / \mathrm{ft}^{2}$ and $0089 \mathrm{~g} / \mathrm{l}$ respectively. This is signiticantly less than the single parameter sub-critical areal density $\left(231 \mathrm{~g}^{\prime} \mathrm{ft}^{2}\right)$ and concentration ( $7.3 \mathrm{~g} / \mathrm{l})$ limits (3] given for Pu-239 in uniform aqueous solutions. The subcritical limits of reference 3 were derermined for a solution of $\mathrm{Pu}\left(\mathrm{NO}_{3}\right)_{4}$ bus are conservative when applied to waste tank sludge because $N$ and $O$ are replaced in part with stronger neutron absorbers such as the diluents listed in table 3 . Washing the sludge may reduce the sludge volume slightly. This would increase the fissile material concentration but would not affect the areal density To increase the equivalent Pu-239 concentr-- :on from $0.089 \mathrm{~g} / \mathrm{l}$ to $7.3 \mathrm{~g} / \mathrm{l}$, the sludge volume would need to be reduced to $1.2 \%$ of $\therefore$ current volume, which is essentially impossible due to the low concentrations of sludge components removed during washing. Tank 42 and 51 contents will remain safe once combined after washing based on the low fissile material areal density and concentration.

Table 3. Weight Ratios of Diluents to Fissile Material For Tanks 42 and 51.

\begin{tabular}{lcccc} 
& \multicolumn{2}{c}{ TANK S1[9] } & & TANK 42[10,13] \\
Diluent & $\begin{array}{c}\text { Wt. Ratio } \\
\text { to Pu-239 }\end{array}$ & $\begin{array}{ll}\text { [o U-235 } \\
\text { to Putio }\end{array}$ & $\begin{array}{c}\text { Wt. Ratio } \\
\text { Wo Pu-239 }\end{array}$ & $\begin{array}{c}\text { Wt. Ratio } \\
\text { to U-235 }\end{array}$ \\
\cline { 2 - 3 } & 1410 & $\frac{1560}{2860}$ & 1410 \\
$\mathrm{Al}$ & 412 & 455 & 1050 & 517 \\
$\mathrm{U}-238$ & 174 & 192 & 357 & 176 \\
$\mathrm{Mn}$ & 146 & 161 & 476 & 235 \\
$\mathrm{Mg}$ & 71 & 78 & 166 & 82 \\
$\mathrm{Ni}$ & 17 & 18 & 46 & 23 \\
$\mathrm{Cr}$ & 9 & 10 & 18 & 9 \\
$\mathrm{Hg}$ & 1 & 1 & 127 & 63
\end{tabular}

Reference 5 documents the abundance of neutron absorbing materials that are present in waste tank sludge, specifically $\mathrm{Fe}$ and $\mathrm{Mn}$. In order to take credit for the neutron absorbing properties of $\mathrm{Mn}$ and $\mathrm{Fe}$, they must remain in the sludge during and after ESP processing. Sludge samples from tanks 72 and 51 confirm an abundance of $\mathrm{Mn}$ and Fe. even after being washed several times The abundance of $\mathrm{Fe}$ and $\mathrm{Mn}$ in the sample results confirms that they remain primarily insoluble and thus remain in the sludge. Table 4 gives the amount of Fe and Mn removed from tank 42 during the 1982/83 ESP demonstration. The amount of $\mathrm{Mn}$ and Fe that was decanted during the ESP demonstration was insignificant when compared to the amouht that remained insoluble [6]. In some instances the $\mathrm{Mn}$ and $\mathrm{Fe}$ concentrations in the supernate were below the detection limit of the analytical equipment. The solubility of $\mathrm{IIn}$ and $\mathrm{Fe}$ in the alkaline waste tank supernate has historically been low. This is consistent with the lfterature $[14,15,16]$ on $\mathrm{Mn}$ and Fe compounds in alkaline solutions. 
WVSRC-TR-93-115

Rev 0

Page 5

Table 4. Materials Transferred Out of Tink 42 During ESP Demonstration. [6]

\begin{tabular}{|c|c|c|c|c|c|}
\hline Process Sten & $\begin{array}{l}\text { Vol. } \\
\text { (kgal) }\end{array}$ & $\begin{array}{c}\text { L' } \\
\text { kggs }\end{array}$ & $\begin{array}{l}\text { Pu-239 } \\
\text { grams }\end{array}$ & $\begin{array}{l}\mathrm{Fe} \\
\underline{\mathrm{kgs}}\end{array}$ & $\begin{array}{l}\text { Mn } \\
\text { kgs }\end{array}$ \\
\hline Slurry; Transter & $6+2$ & 2.9 & $6+$ & $-\cdots$ & 0.3 \\
\hline Al Dissolution & 424 & 204 & +7 & 24 & 37 \\
\hline First W'ash & 937 & 35 & 0.35 & $\ldots$ & -- \\
\hline Second Wash & $9+2$ & 07 & 029 & 39 & 1.4 \\
\hline Third Wasti & 527 & $\underline{06}$ & 012 & 2.4 & 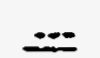 \\
\hline Total & $3, \overline{472}$ & 28 & 12 & $\overline{8.7^{\star}}$ & $\overline{5 . f^{*}}$ \\
\hline
\end{tabular}

*Partial Total

-.- Below detection limit

Table 5 compares the weight ratios of Fe and $\mathrm{Mn}$ to Pu-239 and U-235 found in tank 42 and 51 sludge samples to calculated safe weight ratios $[11,12]$. A documented fissile equivalency between U-235 and Pu-239 in waste tank sludge has not yet been published; however, due to the excessive margin of safety a simplistic conservative equivalency model can be used. Safe weight ratios of $\mathrm{Fe}$ and $\mathrm{Mn}$ to $\mathrm{Pu}-239$ are greater than the safe weight ratios of $\mathrm{Fe}$ and $\mathrm{Mn}$ to $\mathrm{U}-235[11,12]$. It is reasonable to assume that when U-235 and Pu-239 exist together, the safe weight ratios of $\mathrm{Fe}$ and $\mathrm{Mn}$ to this combination will be no greater than for an equal proportion of Pu-239. Employing this approach shows the existing Fe and $\mathrm{Mn}$ to equivalent $\mathrm{Pu}-239$ (U-235 + Pu-239) weight ratio is approximately 7 times the infinite safe value. Applying only the $\mathrm{Fe}$ and $\mathrm{Mn}$ safe weight ratios is conservative since no credit is taken for several other diluents that are significant neutron absorbers such as those in table 3 .

Table 5. Comparison of Fe and . 1 ln to U-235 and Pu-239 Weight Ratios vs. Calculated Safe Weight Ratios. $[11,12]$

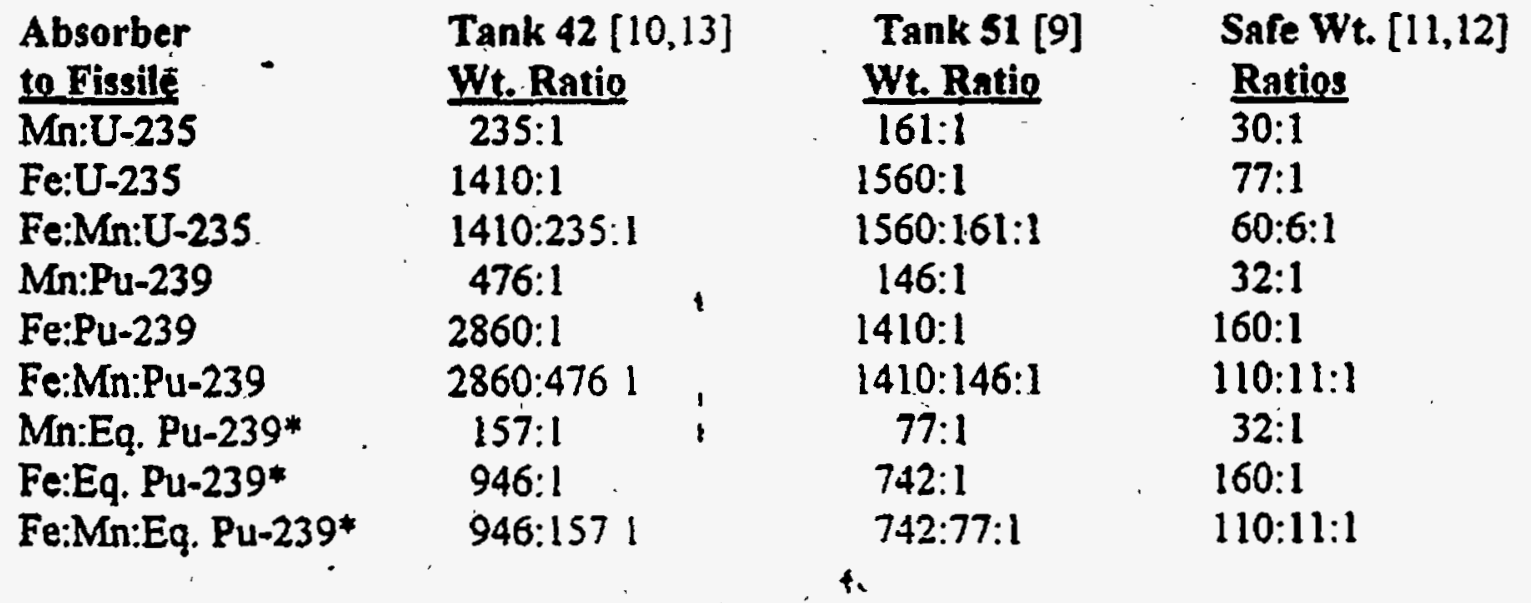

*All U-235 assumed to be Pu-239 for co:t:s:!r:son to safe Pu-239 weight ratios. 
WISRC-TR-9j-115

Rev 0

Page 6

\section{Sludge Wash Water}

Criticality in waste tank supernate is incredible due to the very dilute concentrations of fissile material. Lranium and plutonium solubility $[17]$ in the alkaline supernate of the waste tanks is several orders of magnirude lower than that required for criticality The maximum Pu-239 and $U$ concentration of the water washes during the 1982 ESP demonstration were $0.0001 \mathrm{mg} / \mathrm{l}$ and $10 \mathrm{mg} / \mathrm{l}$ respectively [6] To assess the safety margin, compare to subcritical concentration limits for $P u-239$ and $U-235$ of $7.3 \mathrm{~g} / 1$ and $11.6 \mathrm{~g} / \mathrm{l}[3]$ respectively. The wash water used in ESP is inhibited with $\mathrm{NaOH}$ for corrosion prevention, thus the chemistry throughout ESP operations remains alkaline.

\section{Salt Precipitate From Evaporated Wash Water}

As stated earlier, $U$ and $\mathrm{Pu}$ are only slightly soluble in alkaline waste tank supernate [17]. Thus the amount of $\mathrm{Pu}$ and $\mathrm{U}$ in supernate is a fraction of that found in sludge. This is true of sludge wash water as well. The volume reduction associated with evaporation concentrates the $U$ and $\mathrm{Pu}$ along with all other dissolved solids in the wash water. If the volume reduction concentrates any of these solids past their solubility limit, they crystallize and precipitate from solution. If $U$ and/or Pu precipitate and somehow selectively accumulate, the potential would exist for a criticality. If this precipitation occurs in a waste tank, the fissile material is distributed and safe. If the precipitation and accumulation occurred in the bottom of the evaporator, it may not be. Please note that the evaporator vessel is an inverted cone and its design incorporates a steam lift to prevent solids accumulation [18], however in this assessment it is not necessary to take credit for this feature.

Tank 42 and tank 51 contain $U$ that is at or less than the.U-235 content in natural $U 2.10$. When these tanks are washed during sludge processing, any $U$ that is removed by the wash water will remain subcritical regardless of its concentration, geometry or total mass. This is wholly due to the uranium-235 isotope deficiency. The only fissile material of concern in further washing of the sludge is plutonium. Sample data from the tank $\mathbf{4 2}$ sludge processing demonstration [6] shows that plutonium remains predominantly in the sludge during aluminum dissolution and sludge washing. Table 4 shows the amount of uranium and Pu-239 that left tank 42 during the 1982 ESP demonstration. 'These amounts are based on sample data from the demonstration and the amount of supernate transferred. Precipitating solutions with Pu concentrations similar to those of the ESP demonstration is clearly safe when compared to a safe Pus $=39$ mass of 450 grams [3].

Due to the complex chemistry of high level liquid waste, it is difficult if not impossible to predict the exact mass of soluble Pu that may be transferred into the evaporator system, though the quantity would always be bounded by solubility. Historical supernate sample 
data indicates it will be small. The ESP demonstration data also indicates it will be small. The Pu concentrations from sample data and the ESP demonstration data are many times less than solubility would predict due to the fact Pu is not being dissolved and/or the kinetics of dissolution are extremely slow [17].

The ESP supernate will be sampled for Pu to contirm that Pu' is not being transferred to the evaporator system in quantities that may impact safe operation. When this sample is pulled, it will be analyzed for $\mathrm{U}$. Mn and $\mathrm{Fe}$ as well. Knowing the concentration of these elements in the decanted ESP supernate and the volume of the decant will also allow HILWE Criticality Safety to confirm the safe ratios in the sludge are maintained. The concentration sample results will continue to provide data on $\mathrm{Pu}$ and $\mathrm{U}$ solubility.

\section{CONCLUSIONS}

Sludge samples of tank 42 and 51 show dilute concentrations of fissile material with an abundance of $\mathrm{Fe}, \mathrm{Mn}$ and other diluents. The fissile material concentration and areal density are less than published single parameter fissile niaterial limits, which are established in the absence of $\mathrm{Fe}, \mathrm{Mn}$ and the other neutron absorbing diluents. The sample data are consistent with the estimates from accountability and waste history in terms of dilute concentrations of fissile material and $U$ at or below the U-235 content of natural $U$. Both tanks' contents have been slurried and well mixed. The Fe and Mn to fissile material weight ratios are in tremendous excess of the calculated safe values. If credit were taken for the other neutron absorbing diluents present in the waste, the margin of safety would greatly increase. Mn and Fe remain predominantly in the sludge throughous Al dissolution and sludge washing. The large margin of safety associated with the $\mathrm{Fe}$ and $\mathrm{Mn}$ to fissile material weight ratios will not be impacted by continued washing of tanks 42 and 51 .

Since the $U$ in tanks 42 and 51 is at or below the $U-235$ content of natural $U$, any amount of $U$ that is removed from sludge and transferred to the evaporator system will be safe regardless of total mass, geometry or concentration. This is entirely attributable to the U235 isotope deficiency. Sample results from the ESP demonstration showed that Pu followed dilution throughout Al dissolution and sludge washing. These sample results also found that the Pu concentration in the decants during the ESP demonstration were approximately three orders of magnitude less than that of the U. Transferring tens of grams quantities of Pu-239 contained in hundreds of thousarids of gallons of wash water. to the evaporator system will not impact safe operation. If the entire wash volume were boiled to dryness, there would be insufficient material for criticality. There is no evidence to indicate that this chemistfy will change with continued washing. 
WVRC-TR-93-115

Rev 0

Page 8

\title{
ACTIONS
}

After settling and prior to decant. ESP supernate will be sampled for Pu, L, Fe and .Mn. The analysis will determine the concentration of $\mathrm{Pu} . \mathrm{L}, \mathrm{Fe}$ and .Mn in the wash water decanted In addition, isotopic analysis will be performed on $\mathrm{Pu}$ and $\mathrm{C}^{\circ}$ to confirm the sludge sample, accountability and waste history estimates. L'sing this information along with the volume of the decant, an estimate of the amount of these materials that are removed from the tanks can be performed. The sample results will not be used as a control since there are no controlling limits The sample results will be used by HLWE to confirm that the $M \mid n$ and Fe to fissile material weight ratios are still in excess of the calculated safe weight ratios and to determine the amount of fissile material transferred to the evaporator system. Confirmation through sampling is the most conclusive method available to demonstrate safe operation and to build upon the technical safety basis.

\author{
REFERENCES \\ r. \\ \{e' ${ }_{1}[1] \quad$ WSRC-RP-92-1166, Rev. 1, W. S. Cavin, "Uranium Precipitate Characteristics \\ and Tank 42 Fissile Content"(U). November 18,1992. \\ [2] C. J. Coleman, N. E. Bibler, R. A. Dewberry, "Analyses of High Level Radioactive \\ Glasses and Sludges at the Savannah River Site": Proceedings of Waste \\ Management '90, Tuscon, AZ, pp 651-657. \\ [3] ANSUANS-8.1-1983, Nuclear Criticality Safety in Operations With Fissionable \\ Materials Outside Reactors \\ [4] WER-HLE-921217, Crumm to Clemmons, "Tank SI Fissile Material Estimation" \\ (U), November 18, 1992. \\ [5] WER-WME-921007, Revision 1, Clemmons to Chandler, "Nuclear Criticality \\ Safety of Waste Tank Sludge For ESP" (U), August 12, 1992. \\ [6] WER-FILE-930561, Clemmons to Chandler, "Effect of ESP on Waste Tank \\ Sludge U, Pu, Fe and Mn Content (U)", February 10, 1993. \\ [7] \\ WSRC-RP-91-78-3B, "Waste .l1anagement Monthly Data Record", March 1991 \\ (U) \\ C8] WSRC-RP-92-78-9B, "Waste 19 Inzgement Monthly Data Record", September \\ 1992. (U) \\ [9] SRT-CTS-92-242, Cavin to Clem- n: Mnk 51 Diluent to Fissile Ratios", \\ 11/18/92.(U)
}


- WSRC-TR-93-115

Rev. 0

Page 9-

$V$ [10] WSRC-RP-93-262, Bibler. Wyrick, Dewberry and Coleman to Holtzscheiter and Coffey, "Lranium and Plutonium Concentrations and Isotopics in Tank 42 Sludge Slurry" (U), February 25.1993

[11] WER-WIIE-921143, Clemmons. Gosien to Chandler, NCSA W.T-92-3, "Minimum Safe Ratios of Fe and Mín to L-235 in an Infinite System" (U), September 18, 1992.

4 [12]

WER-HLE-921353, Clemmions, Gosien to Chandler, NCSA WM-92-5, "Minimum Safe Ratios of Fe and $\mathrm{Mn}$ to Pu-239 in an Infinite System" (U). November 25 , 1992.

WSRC-RP-93-265. Bibler, Wyrick, and Coleman to Holtzscheiter and Coffey, "Concentrations of Major Elements in Tank 42 Sludge Slurry" (U), February 25, 1993.

14] A. Seidell, Solubilities of Inorganic and Metal Organic Compounds, 4h edition, Van Nostrand, New York, 1965, Volume II, page 558.

415] A. Seidell, Solubilities of Inorganic and Metal Organic Compounds, $3^{\text {rd }}$ edition, Van Nostrand, New York, 1940, Volume I, page 1004.

416] A. Seidell, Solubilities of Inorganic and Metal Organic Compounds, $4^{\text {th }}$ edition, Van Nostrand, New York. 1965, Volume I, page 1038-1039.

$\checkmark$ [17] WSRC-TR-93-056, "Solubility of Plutonium and Uranium in Alkaline Salt Solutions (U)", February 12, 1993.

WSRC-TR-93-081, "Evaluation of Potential Accumulation of Uranium and/or Plutonium in the HLW Evaporator Systems (U)", February 1,1993 
WSRC-TR-93-115

Rev. 0

Page 10

\section{DISTRIBUTION}

Tank Farm Criticality Safety

Senior Management Review Group:

F. F. Cadek, 719-4A

F. Beranek, 773-A

L. M. Papouchado, 773-A
Task Farm Criticality Safety

Senior Technical Review Group:

M. D. Boersma, 704-T

W. S. Durant, 992 W-1

M. C. Thompson, 773-A

P. D. d'Entremont, 703-H

J. P. Morin, 719-4A

R. A. Scaggs, 703-H

T. A. Reilly, 707-F

\section{General Distribution:}

WMER Management:

N. C. Boyter, 703-A

C. L. Peckingpaugh, 719-4A

\section{SRTC:}

W. L. Tamosaitis, 773-A

J. R. Schomhurst, 992-1W

M. K. Gupta, 992-1W

\section{Operations:}

V. G. Dickert, 703-H

R. G. Croley, 241-120H

G. D. Thaxton, 241-120H

J. N. Brooke, 241-120H

W. B. Van Pelt, 241-120H

E. D. Lee, 241-152H

J. R. Chandler, 703-H

N. T. Hightower III, 719-4A

Centrals ond 703-A

WMT Files, 703-H

File Code 21.6

G. T. Wright, 703-H

H. M. Handfinger, 241-120H

C. J. Baker, 241-120H

E. Ennis, $241-120 \mathrm{H}$ 


\section{UUMIVIUAL KEVIEV COVER PAGE}

Date: $3 / 18 / 93$

From: James S. Clemmons, 703-H

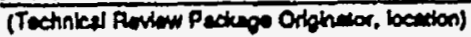

Technical Roviow No.

SR-HLE-93-557

Indirect Work Request No. Procedure As., or other Proposed Activity No.

WSRC-TR-93-115 - Qddexd um

\section{Involving Evaporation of ESP Batch one Wash Water \\ WM-NS-7012, "Technical Reviews", and contains the following:

$\begin{array}{llll}\text { Design Inpul Form } & 0 & \text { Included. (For Indirect Work Roquests Only) }\end{array}$

Title: Potentlal Inadequacy in the Authorizatlon Basis for Criticality Safety

The attached HLWE Technical Review Package (reterenced above) has been prepared in accordance with

Screening Process Hazards

[ Included

Reviow Report (SPHR)

付 Nol included per Proceduro WM-NS-7012

Not included per the following:

For operating procodures that will not require a SPHR, specify (below) the Periodic PHR (or other applicable PHR) that affects or is related to the procedure. For procedures that are (or should be) designated " $Q$ ", ensure that the PHR and Action llem (or recommendation) numbers are listed in the procedure, and include the PHR\# and related comments on the Procedure Review Sheot.

Periodic PHR\#: $200-$ N/A

Unreviewed Safety

Question Determination

(USQD)

WM Environmental Compliance Checklist (ECC)

other comments 住cluded

D Not inctuded per Procodure WM-NS-7012

D Not included per the following:
(1) Included

Not included per Procidure WM-NS-7012

$\square$ Not included per the following:

IECHNICAL REPORT, WSAC-IR-93-115. provides a sueplemental analusis of criticality safety imoact of evaporating ESP baich one wash water supplementing Saleby Analysis Report DPSTSA-200-10-Sup-18 and Authorization Basis Document, WSRC-TR-93-081.

\section{Distribution: \\ WME Flle, 703H, Code 6.2}

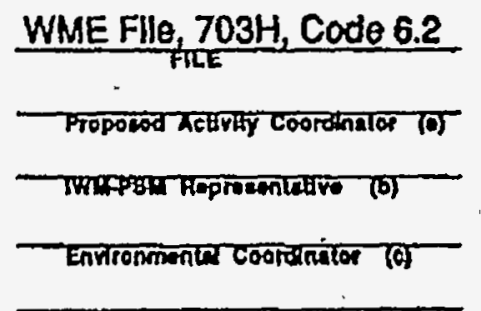

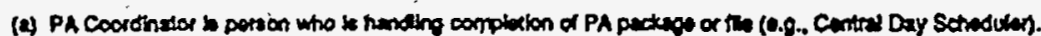

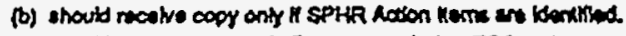

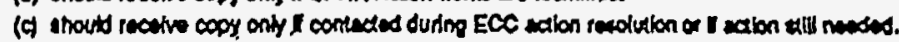

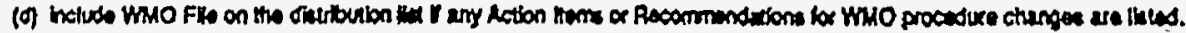

G.D. Thaxton, 241-120H

W. B. Vanfelt, 241-152H
M.A. Coravolo, 703-H

M. S. Pelers, 703-F
E.D. Lee, 241-152H

J.E. Marra, 703-H

M.C. Chandler, $703-\mathrm{H}$

C.G. Lampley, 241-120H 


\section{PRÓPOSED ACTIVITY TITLE: Polential Inadequecy In the i Authorizalion Basle for Criticallty Sefoty Involving Evuporatlon of ESP Batch Óne-When Waler}

A.1 Descriptlon of Proposed Aefluity (or Diecovery): (can cay 'sae SPHA' ll altachod)

Tochrical Ropon. WSAC-TR-23-081, and aseodated USQD SA-HLE-93-341, ovalualad the, criticality saloty aspocts of the Tank Farm ovaporator syateme end concluded the evaporator systeme hore sale under all expected condions. ESP wash walor was recognized in

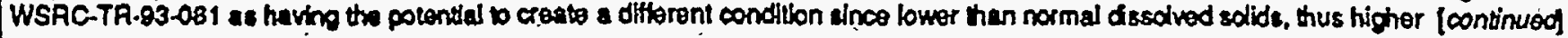

Proposed Activiv Reterenco Docemente:

The relerence documente are Techicel Report WSAC-TR-23-115, Tectnical Repon WSRG.TR-93-081, and DOE A5sessment Feport 93.0408017.

Have all pending "Safely Documents" of the Authorization Basis been considered? (NA If no changes pending)? I INA I INo [X] Yes

A.2 is change to the Authorization Bats required?

Bifferencea: (1) Tochnical Sunderd (DPSTS-241).

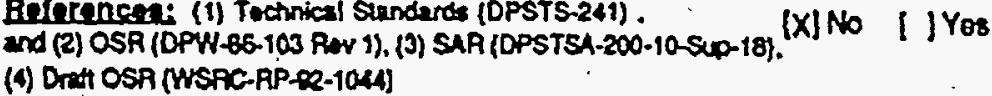

Ressons / Reterences:

Technical Roport WSRC-TR-23-115 upports the concusion in the SAR, DPSTSA-200-10-Sup-18, and Technical Roport WSRC-TR-93-081, 10. no crodible mecheniem Idantifiod to soloctivaly concentrate and accumulale a critical mass in the SRS HLW evaporators. Tochnical Report WSAC-TR-93-115 spocliferly evaluales the evaporation of ESP wash water for DWPF studge balch ons (including current wash wate//supernate) and concluded there ts no crilkality concem. Sludos batch one is currently in tanks 51 and 42.

If the anower to A.2 is "Yes", Proceod to Part ll of this form to complete the USQ Safety Evaluation (A.4).

\section{A.3 Scrouning Quastions}

Doos the Proposod Activity Involive a:

(1) Change to the facllty as deccribed in the Authorization Basis? ReasorizPolerences (list section ts reviewed):

[X] No I J Yes

This USOD ecreoning provides supplemental inlormation to support cribcakity safory of ESP processing of DWPF sludeo feed batch ore wash water from tanks 42 and 51 in respense to the DOE Liquid Waste Division Assessment Report 93-04-08-017. The proposed activity addressed by this USOD does not hrotve a change to the faclilty.

(2) Change to procedures or methods (other than minor changes), as described in the Authorization Basis? Reasons/Roferencos (ist section to revlownd):

(X) No I Y Yes

This USCD screening provides supplemental information to support cribcalify salety of ESP processing of DWPF sludoe teed batch one wash wator hom tanks 42 and $51 \mathrm{~h}$ response to the DOE Liquid Waste Dhiston Assessment Report 23-04-08-017. The proposod activity adfresead by this USOD does not involve changes 10 procedures of methods.

(3) Test or experiment not described in the Authorization Basis? Reasons/Ralerences:

[X] No I Y Yos

This USCD scrooring providos supplamental inlomsion wo suppon criticality saloty of ESP processing of DWPF sludge lood batch one wash water from tarks 42 and 51. The proposed activity addressed by this USOD does not imolvo a test or experimenL.

(4) Analytical errors, omissions, or Inadequades in the Authorization Basis? Reasons/Rolerences: (X)No / YYes SAA section 5.4.1 discusses the potental for criticality h weste tanks as woll as evaporaiors. These discussions include fissile concentrattons in skudge, posstbilty of transfer emors from Canyon facilites, as well as the possibility of abnomally tigh fissile content waste boing tansterred from the Caryon facilty into the evaporator foed tank and through an ovaporator. [continued

If any question h A.2 of A.3 ks answored as "Yos", procede to Part ll of this Form to comploto tho Use Evaluation safoty evaluation (A.4). If a Authoxization Bacis chango is requited, the USOD Orlginator Initiales the process.

Is a USO Evaluatori (A.4.) roguked?

NOTE: Use additional sheste throughout the form se neseseary.

James S. Clammons _ 1703-H

USCD Orginatornocation (orint)

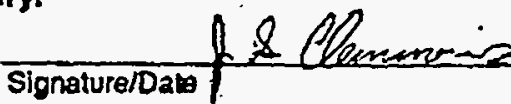

[X]No I J Yes

Do you agreo with the USOD Orginator's USO Screening?

"No". slate reason(s) selesences and return to USOD Origirator.

$$
\text { , I INO EIYes }
$$

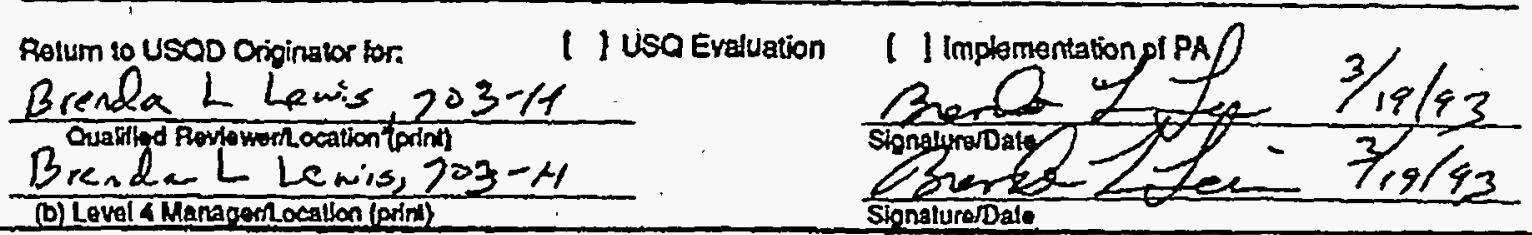

INOTE: (a) Parts II and III of this Iorm are nat roguted $\mathrm{K}$ USODO and OR apro ithat USO Evaluation is not nooded.

(b) LA ktanager sions only al discretion of OR. OR should NA and inilial II nct neaded.] 


\section{PART I USQ Screening}

\section{A. 1 continued}

... volume reduction factors would be present in this stream. DOE LWD Assessment Report 93-04-08.017 also identified that additional evaluation of the ESP wash water was needed before processing this stream.

Technical report WSRC-TR-93-115 addresses the criticality safety of washing the DWPF sludge feed batch one currently contained in tanks 42 and 51 . The report shows that sending wash water with uranium and plutonium concentrations similar to those observed in the 1982/83 ESP demonstration is safe and expected. Criticality safety of ESP washing on batch one is concluded based on the uranium-235 isotope deficiency of the uranium inventory and due to the extremely low plutonium concentrations that were characteristic of the ESP demonstration decants. $\mathrm{U}$ and $\mathrm{Pu}$ analysis of tank $\$ 1$ supernate confirms this safety basis.

Aluminum dissolution is the only part of ESP known to solubilize a significant mass of fissionable material, uranium. As stated earlier, the uranium inventory in tanks 42 and 51 is depleted in the U-235 isotope and thus not a criticality issue. In addition, aluminum dissolution will not be performed again on the first batch of DWPF sludge feed. Thus this USQD addresses washing the first batch of DWPF sludge feed currently contained in tanks 42 and 51 relative to criticality safety, including evaporation of current and future generated wash water.

\section{A.3(4) continued}

Evaporation of ESP wash water is not currently considered adequately addressed in the SAR or Authorization Basis document WSRC-TR-93-081. Evaporation of wash water from DWPF sludge feed batch one has been evaluated in WSRC-TR-93-115. The report concludes there is no criticality concern during processing of batch one and evaporation of the wash water.

After settling and prior to decant, ESP. supernate will be sampled. The analyses will include determining the concentration of $\mathrm{Pu}, \mathrm{U}, \mathrm{Fe}$ and $\mathrm{Mn}$. In addition isotopic analyses will be performed on $\mathrm{U}$ and $\mathrm{Pu}$ to confirm the sludge sample, accountability and waste history estimates. The sample results will be used by HLWE to confirm that the Mn and Fe to fissile material weight ratios are still in excess of the calculated safe weight ratios and to determine the amount of fissile material transferred to the evaporator system. $\mathrm{Pu}$ and $U$ sample results for the supernate currently in tank 51 has been evaluated and confirms no criticality safety issue for evaporation of this material. Sampling ESP supernate prior to future transfers is outlined in procedure 241-H-2007. 